\title{
Peningkatan Kepuasan Mahasiswa dalam Pembelajaran E- Learning melalui Task Technologi Fit dan Kualitas Informasi
}

\section{Yuni Kasmawati ${ }^{*}$, Aris Wahyu Kuncoro ${ }^{2}$}

1,2 Fakultas Ekonomi dan Bisnis Universitas Budi Luhur, Indonesia

\section{ART ICLE INFO}

Article history:

Received August 14, 2021

Revised August 17, 2021

Accepted October 10, 2021

Available online October 25, 2021

Kata Kunci:

Task Technology Fit, Kualitas

Inforamsi, Kepuasan Mahasiswa

Keywords:

Task Technology Fit, Information Quality, Student Satisfaction



This is an open access article under the CC BY-SA license.

Copyright (๔) 2021 by Author. Published by Universitas Pendidikan Ganesha.

\begin{abstract}
A B S T R A K
Pandemi Covid 19 di awal tahun 2020 menyebabkan perubahan metode pembelajaran tatap muka menjadi metode pembelajaran berbasis online. E-learning merupakan salah satu metode pembelajaran berbasis olline yang akhirnya menjadi kebutuhan dan tumpuan saat pandemi. Penggunaan teknologi yang tepat akan mendukung proses pembelajaran. Untuk itu, teknologi harus dapat dimanfaatkan dan sesuai dengan kebutuhan, sehingga mampu mendukung tugas. Kualitas informasi yang up-to-date, akurat, relevan, dan tepat diperlukan guna mendukung proses pembelajaran, sehingga keduanya dapat memberi dampak positif bagi pengguna. Tujuan penelitian ini untuk mengetahui pengaruh Task Technology Fit (TTF) dan kualitas informasi terhadap kepuasan mahasiswa. Penelian ini merupakan penelitian kuantitatif dengan melibatkan 198 sampel mahasiswa. Metode analisis menggunakan Structural Equation Modeling dengan pendekatan Partial least square (SEM-PLS). Hasil penelitian menunjukkan bahwa TTF berpengaruh signifikan terhadap kepuasan mahasiswa. Kualitas informasi berpengaruh signifikan terhadap kepuasan mahasiswa. Dengan demikian perlu diperhatikan faktor pendorong kepuasan mahasiswa dalam pembelajaran e-learning dari sisi Task Technologi Fit dan kualitas informasi, sehingga tujuan pembelajaran dapat tercapai.
\end{abstract}

\section{A B S T R A C T}

The Covid 19 pandemic at the beginning of 2020 caused a change in face-to-face learning methods to online-based learning methods. E-learning is one of the online-based learning methods that eventually becomes a necessity and a foundation during a pandemic. The use of appropriate technology will support the learning process. For this reason, technology must be utilized and in accordance with needs so that it is able to support the task. The quality of up-to-date, accurate, relevant and precise information is needed to support the learning process so that both can have a positive impact on users. The purpose of this study was to determine the effect of Task Technology Fit (TTF) and the quality of information on student satisfaction. This research is quantitative research involving 198 student samples. The method of analysis uses Structural Equation Modeling with Partial least squares approach (SEM-PLS). The results showed that TTF had a significant effect on student satisfaction. The quality of information has a significant effect on student satisfaction. Thus, it is necessary to pay attention to the factors driving student satisfaction in e-learning in terms of Task Technology Fit and the quality of information so that learning objectives can be achieved.

\section{PENDAHULUAN}

Pandemi Covid 19 yang melanda Indonesia pada awal tahun 2020 lalu memberi konsekuensi kepada masyarakat untuk mengurangi aktivitas bertemu secara langsung agar wabah pandemi segera tertangani. Hal ini berdampak di berbagai sektor, termasuk sektor kependidikan. Di sektor pendidikan pemerintah Indonesia memutuskan untuk mengalihkan semua kegiatan pembelajaran yang selama ini dilakukan dengan sistem tatap muka ke sistem pembelajaran berbasis online agar tujuan pembelajaran tetap tercapai (Hadi, 2020; Pakpahan \& Fitriani, 2020). Salah satu metode pembelajaran berbasis online yaitu e-learning. E-learning merupakan sarana pembelajaran yang efektif saat pandemi Covid 19 bahkan merupakan salah satu komponen utama dalam menyediakan pendidikan online, sehingga menjadi 
kebutuhan dan tumpuan kegiatan pembelajaran (Amalia \& Purwaningsih, 2020; Sawangchai, Prasarnkarn, Kasuma, Polyakova, \& Qasim, 2020). Pembelajaran secara e-learing juga terbukti menjadi satu-satunya pilihan pembelajaran berkelanjutan di masa pandemic Covid 19 (Sari \& Trisnawati, 2021; Sawangchai et al., 2020). Pembelajaran tersebut menawarkan banyak keunggulan dibanding metode konvensional termasuk dalam hal akses yang lebih besar pada materi pembelajaran, komunikasi lebih cepat dan kolaborasi akademik (W. M. Al-Rahmi et al., 2019; Alam et al., 2021). Bahkan penelitian yang dilakukan (W. M. Al-Rahmi, Othman, \& Yusuf, 2015; Alam et al., 2021) menunjukkan adanya efektivitas program $e$ learning.

Pembelajaran e-learning merupakan pembelajaran yang memanfaatkan teknologi selama proses pembelajaran (Cidral et al., 2018; Al-Fraihat et al., 2020). Pembelajaran tersebut membutuhkan tiga komponen utama yaitu teknologi sistem informasi, kualitas layanan elektronik dan kualitas informasi elektronik (Sawangchai et al., 2020). Mengingat pentingnya hal tersebut, maka teknologi yang digunakan hendaknya mampu mendukung seluruh kegiatan proses pembelajaran. Untuk itu, agar teknologi informasi tersebut memiliki dampak positif terhadap kerja individu (yaitu pelaksanaan tugas), maka teknologi harus dimanfaatkan dan harus sesuai dengan tugas yang didukungnya atau disebut dengan istilah Task Technologi Fit/TTF (Goodhue \& Thompson, 1995). Sehubungan dengan kecocokan teknologi dengan tugas tersebut, TTF mengacu pada bagaimana teknologi memenuhi kebutuhan tugas pengguna dan merupakan fungsi dari karakteristik sistem dan karakteristik tugas (Goodhue \& Thompson, 1995). Sehingga kesesuaian tugas dan karakteristik tugas pada gilirannya akan menentukan penggunaan dan kinerja pengguna (Gebauer et al., 2010; B. Wu \& Chen, 2017).

TTF diartikan sebagai sejauh mana teknologi membantu pengguna dalam melakukan pekerjaan atau sejauh mana sistem cocok untuk memberikan bantuan yang cukup dalam menyelesaikan tugas dan memenuhi kebutuhan mereka (Isaac et al., 2017; Almaiah et al., 2020). Terkait dengan sistem pembelajaran, manfaat TTF berhubungan dengan kegiatan berbagi pengetahuan, pengumpulan dan analisis atau konstruksi (Akkoyunlu dan Soylu, 2008). Model TTF banyak digunakan untuk mengevaluasi bagaimana teknologi informasi menghasilkan kinerja, mengukur dampak penggunaan teknologi dan menilai kecocokan antara tugas dengan karakteristik teknologi (Gebauer et al., 2010; Al-Rahmi et al., 2020). Telah diidentifikasi bahwa karakteristik tugas, karakteristik teknologi, dan karakterisitk individu sebagai penentu TTF (Goodhue \& Thompson, 1995; Navarro et al., 2021). Kualitas informasi merupakan elemen penting yang perlu dipertimbangan dalam mementukan keberhasilan e-learning (Al-Fraihat, 2020; Alam et al., 2021). Kualitas informasi didefinisikan sebagai sejauh mana pengguna internet yakin bahwa informasi internet up-to-date, akurat, relevan dan tepat serta lengkap dengan tampilan dan format yang baik, mudah dipahami dan mudah ditafsirkan (Abrego Almazán, Sánchez Tovar, \& Medina Quintero, 2017; D. Cheng, Liu, Qian, \& Song, 2013; Gorla, Somers, \& Wong, 2010). Dalam konteks pembelajaran online, kualitas informasi terdiri dari kualitas konten, kualitas konteks dan tautan (Wu dan Wang, 2006).

Kepuasan pengguna didefinisikan sebagai sejauh mana pengguna internet puas dengan keputusannya untuk menggunakan internet dan seberapa baik memenuhi harapannya (Wang dan Liao, 2008; Isaac et al., 2017). Kepuasan siswa sebagai sejauh mana media sosial dapat memberikan informasi yang dibutuhkan siswa (Al-Maatouk et al., 2020; Almarashdeh, 2016). Sementara itu kepuasan pengguna banyak digunakan dalam mengukur keberhasilan sistem informasi (Kanellou dan Spathis, 2013; Montesdioca dan Maçada, 2015) misalnya e-learning (Mohammadi, 2015). Variabel-variabel utama dan penting dalam memprediksi kepuasan pengguna terhadap teknologi yang digunakan yaitu kegunaan yang dirasakan dan kemudahan penggunaan yang dirasakan (Moore, 2011).

Penelitian yang dilakukan terhadap karyawan kementerian pemerintahan Yaman menyimpulkan bahwa TTF memiliki pengaruh positif terhadap kepuasan pengguna (Isaac et al., 2017). Penelitian terhadap mahasiswa menyimpulkan bahwa TTF mempunyai hubungan positif signifikan terhadap kepuasan siswa (Cheng, 2019; Al-Maatouk et al., 2020). Demikian juga hasil penelitian yang menyimpulkan bahwa TTF bepengaruh positif signifikan terhadap kepuasan mahasiswa (Alyoussef, 2021). TTP juga berpengaruh signifikan terhadap kepuasan pengguna di Universitas Nigeria (Osang, 2019). E-informasi diperlukan untuk mendorong kepuasan pengguna dalam membangun e-learning yang lebih kuat (Sawangchai et al., 2020). Seperti hasil penelitian yang menyimpulkan bahwa kualitas informasi berhubungan positif dengan kepuasan pengguna internet (Isaac, Abdullah, Ramayah, \& Mutahar, 2018). Penelitian lain menyatakan bahwa kualitas informasi berpengaruh signifikan terhadap kepuasan pengguna. Dalam konteks pembelajaran e-learning, kualitas informasi memiliki efek positif yang signifikan terhadap kepuasan pengguna seperti hasil penelitian yang dilakukan oleh (Abrego Almazán et al., 2017; Al-Fraihat et al., 2020; Aparicio, Bacao, \& Oliveira, 2017; Main Uddin, Ghosh, \& Isaac, 2019; RamírezCorrea, Rondan-Cataluña, Arenas-Gaitán, \& Alfaro-Perez, 2017).

Penelitian ini perlu dilakukan mengingat kondisi pandemi Covid 19 mengharuskan proses pembelajaran dilakukan secara online. Untuk itu, diperlukan teknologi dan kualitas informasi yang tepat 
dalam mendukung proses tersebut agar tujuan pembelajaran tercapai. Perlu diketahui bahwa teknologi yang digunakan sesuai dengan pengguna. Di samping itu, teknologi yang digunakan sesuai dengan kebutuhan tugas serta kualitas informasi tersebut up-to-date, akurat, relevan, dan tepat. Dengan demikian, mahasiswa merasa puas dengan system e-learning yang ada. Dan pada akhirnya kepuasan yang dirasakan mahasiswa dapat meningkatkan kinerjanya serta tujuan pembelajaran tercapai.

\section{METODE}

Penelitian ini merupakan penelitian eksplanatori yang menjelaskan hubungan sebab akibat yang terjadi antara variable-variabel yang ada. Pendekatan penelitian secara kuantitatif digunakan untuk menguji hipotesis. Populasi penelitian adalah mahasiswa Universitas Budi Luhur Jakarta yang aktif pada semester genap 2020/2021. Jumlah minimal sampel yang diambil mengacu pada pendapat (Ferdinand, 2014; Hair, Risher, Sarstedt, \& Ringle, 2019) yaitu mengalikan banyaknya item dengan 10. Sehingga minimal sampel yang diambil dalam penelitian ini 9 item dikalikan 10 yaitu sebesar 90 sampel. Namun dalam penelitian ini sampel yang diambil sebanyak 198.

Pengumpulan data melalui penyebaran kuesioner dalam bentuk googleform. Kuesioner digunakan untuk mengukur persepsi responden terhadap variabel yang digunakan. Kuesioner menggunakan skala likert 5 poin dengan opsi jawaban sangat setuju (5), setuju (4), netral/cukup (3), tidak setuju (2) dan sangat tidak setuju (1). Setelah data terkumpul, uji validitas dan reliabilitas dilakukan untuk mengetahui ketepatan dan kekonsistenen instrument dalam mengukur. Uji validitas kuesioner dengan melihat nilai corrected item total correlation sedang koefisien Cronbach alpha digunakan untuk menentukan reliabilitas kuesioner. Hasil uji validitas menunjukkan bahwa semua item yang digunakan dalam kuesioner memenuhi kriteria uji validitas dengan nilai corrected item total correlation di atas 0,3 (Setiaji, 2004; Supriyanto \& Maharani, 2013). Sedang nilai cronbach alpha di atas 0,6 menunjukkan item dalam kuesioner memenuhi kreteria uji reliabilitas (Ghozali, 2006; Supriyanto dan Maharani, 2013).

Selanjutnya, data dianalisis menggunakan analisis Structural Equation Modeling dengan pendekatan Partial least square (SEM-PLS). WarpPls 6.0. digunakan untuk menguji model pengukuran dan struktur melalui tiga tahap. Tahap pertama yaitu analisa outer model meliputi indicator validity, convergent validity, discriminant validity, composite reliability dan average variance extracted (AVE). Selanjutnya tahap dua yaitu analisa inner model meliputi koefisien determinasi $\left(\mathrm{R}^{2}\right)$ dan predictive relevance $\left(\mathrm{Q}^{2}\right)$. Dan tahap terakhir yaitu pengujian hipotesis.

\section{HASIL DAN PEMBAHASAN}

Hasil

Penelitian ini bertujuan untuk menganalisis dan menjelaskan pengaruh TTF dan kualitas informasi terhadap kepuasan mahasiswa pada pembelajaran e-learning. Hasil evaluasi outer model pada tabel 1 menunjukkan bahwa nilai loading factor semua indikator diatas 0,7 sehingga persyaratan uji kriteria indicator validity semua indikator terpenuhi (Latan \& Ghozali, 2016). Sedang hasil terkait uji discriminant validity data dilihat pada tabel 2. Dan hasil output terkait uji outer model yang lain serta uji inner model ditunjukkan pada tabel 3 dan gambar 1 . Tabel 2 terkait uji discriminant validity menunjukkan bahwa nilai akar kuadrat AVE setiap konstruk yang terlatak pada garis diagonal lebih besar dari korelasi antar konstruk sehingga tidak ada permasalahan dalam validitas diskriminan. Sedang dari tabel 3 dapat dilihat bahwa nilai AVE untuk semua indikator lebih dari 0,5, sehingga memenuhi kriteria validitas konvergen, nilai composite reliability setiap indikator lebih besar dari 0,7 menunjukkan reliabilitas yang tinggi (Latan \& Ghozali, 2016).

Hasil analisis inner model berdasarkan tabel 3 dapat dijelaskan bahwa nilai $\mathrm{R}^{2}$ sebesar 0,69 menunjukkan model yang dibangun kuat (Latan \& Ghozali, 2016). Artinya, model yang dibangun mampu menjelaskan sebesar 69,0\%, sedang sisanya 31,0\% dijelaskan oleh variabel lain. Sedang nilai $\mathrm{Q}^{2}$ sebesar 0,692 mempunyai arti bahwa model yang dibangun mempunyai predictive relevance yang kuat (Latan \& Ghozali, 2016). Gambar 1 terkait uji hipotesis, menunjukkan bahwa hipotesis 1 diterima dengan nilai $\mathrm{p}$ value $<0,01$ artinya bahwa TTF berpengaruh signifikan terhadap kepuasan mahasiswa. Demikian juga hipotesis 2 diterima dengan nilai p-value $<0,01$. Artinya, kualitas informasi berpengaruh signifikan terhadap kepuasan mahasiswa. 
Tabel 1. Hasil Uji Outer Model

\begin{tabular}{|c|c|c|c|}
\hline Variabel & Indikator, Item & Loading Factor & Ket. \\
\hline \multirow{3}{*}{$\begin{array}{c}\text { Task } \\
\text { Technology } \\
\text { Fit (TTF) }\end{array}$} & $\begin{array}{l}\text { TTF1, E-learning cocok untuk pembelajaran selama } \\
\text { pandemi }\end{array}$ & 0,865 & Valid \\
\hline & $\begin{array}{l}\text { TTF2, Fungsi e-learning sesuai dengan proses } \\
\text { pembelajaran }\end{array}$ & 0,915 & Valid \\
\hline & $\begin{array}{l}\text { TTF3, E-learning memenuhi kebutuhan proses } \\
\text { pembelajarn }\end{array}$ & 0,903 & Valid \\
\hline \multirow{3}{*}{$\begin{array}{l}\text { Kualitas } \\
\text { Informasi }\end{array}$} & KI1, E-learning menyediakan informasi yang terbarukan & 0,931 & Valid \\
\hline & KI2, E-learning menyediakan informasi yang akurat & 0,941 & Valid \\
\hline & $\mathrm{KI}$, E-learning menyediakan informasi yang relevan & 0,944 & Valid \\
\hline \multirow[t]{3}{*}{$\begin{array}{l}\text { Kepuasan } \\
\text { Mahasiswa }\end{array}$} & $\begin{array}{l}\text { KM1, Penggunaan e-learning saat pandemi adalah } \\
\text { keputusan yang bijak }\end{array}$ & 0,895 & Valid \\
\hline & $\begin{array}{l}\text { KM2, E-learning telah memenuhi harapan proses } \\
\text { pembelajaran saat pandemi }\end{array}$ & 0.903 & Valid \\
\hline & $\begin{array}{l}\text { KM3, Secara keseluruhan, mahasiswa puas dengan e- } \\
\text { learning }\end{array}$ & 0,894 & Valid \\
\hline
\end{tabular}

Tabel 2. Hasil Uji Discriminant Validity

\begin{tabular}{lccc}
\hline & TTF & Kualitas Informasi & Kepuasan Mahasiswa \\
\hline TTF & $(0,895)$ & 0,709 & 0,773 \\
Kualitas Informasi & 0,709 & $(0,939)$ & 0,749 \\
Kepuasan Mahasiswa & 0,773 & 0,749 & $(0,897)$ \\
\hline
\end{tabular}

Tabel 3. Hasil Output Program



Gambar 1. Hasil Uji Hipotsis

\section{Pembahasan}

TTF mempunyai pengertian sebagai sejauh mana teknologi atau sistem yang digunakan cocok untuk memberikan bantuan yang cukup dalam menyelesaikan tugas dan memenuhi kebutuhan pengguna. TTF dalam penelitian ini ditinjau dari sisi kecocokan dengan kondisi lingkungan, kesesuaian fungsi dan kesesuaian dengan kebutuhan. Hasil penelitian menujukkan bahwa TTF berpengaruh signifikan terhadap kepuasan mahasiswa. Hal ini mengindikasikan bahwa TTF merupakan faktor pendorong dalam meningkatkan kepuasan mahasiswa selama proses pembelajaran e-learning. Dari ketiga faktor pendorong TTF tersebut, ternyata e-learning yang mempunyai fungsi sesuai dengan proses pembelajaran berperan paling dominan dalam mengukur TTF. Hal ini dilihat dari nilai loading faktor paling tinggi diantara yang lain yaitu sebesar 0,915. Task-Technology Fit (TTF) merupakan salah satu model yang menafaatkan 
teknologi untuk membantu individu dalam pelaksanaan tugas-tugasnyan atau tugas jabatan guna pencapaian kinerja individu (Permana \& Setianto, 2017; Tam \& Oliveira., 2016). Dalam model tersebut, TTF merupakan interaksi antarkarakteristik tugas, teknologi dan individu. Artinya, kemampuan individu dalam menyelesaikan tugas tersebut didukung oleh fungsi dari teknologi. TTF dapat memberikan panduan untuk desain teknologi atau tugas. TTF mengeksplorasi hubungan antara tugas individu dan teknologi profil fit dengan mengukur kinerja pengguna dan pemanfaatan teknologi. Dapat dikatakan bahwa orang akan menerima atau menggunakan teknologi jika teknologi tersebut sesuai atau memenuhi kebutuhan untuk menyelesaikan tugasnya. Oleh karena itu, jika TFF digunakan dalam pembelajaran Elearning akan memudahkan mahasiswa dalam menyelesaikan tugas-tugasnya, sehingga akan berdampak terhadap kepuasaan mahasiswa. Hasil penelitian ini mendukung penelitian yang telah dilakukan sebelumnya oleh (Al-Maatouk et al., 2020; Alyoussef, 2021; Osang, 2019) yang menyimpulkan bahwa TTF berpengaruh signifikan terhadap kepuasan mahasiswa. Penelitian lain menunjukkan bahwa tasktechnology fit berpengaruh terhadap kinerja individual (Wardani, 2019). Artinya ada perkembangan teknologi yang digunakan guna menyelesaikan tugas - tugasnya sehingga mampu meningkatkan kinerja individualnya. Task technology fit berpengaruh terhadap prestasi belajar yang diraih mahasiswa (Yi, Y. J. \& Bae., 2016). Prestasi belajar merupakan suatu hal yang dibutuhkan siswa untuk mengetahui kemampuan yang diperolehnya dari suatu kegiatan yang disebut belajar. Pemanfaatan teknologi informasi yang sesuai dapat meningkatkan prestasi. Hal ini akan mendorong kepuasaan mahasiswa dalam pembelajaran e-learning.

Faktor pendorong kepuasan mahasiswa tersebut berupa kecocokan e-learning untuk pembelajaran selama pandemi, kesesuaian fungsi e-learning dengan proses pembelajaran, dan kemampuan e-learning dalam memenuhi kebutuhan prosen pembelajaran. E-learning yang digunakan sesuai dengan fungsi dan kebutuhan mahasiswa misalnya akses yang lebih besar pada materi pembelajaran dan komunikasi lebih cepat serta kolaborasi akademik (W. M. Al-Rahmi et al., 2019; Alam et al., 2021), sehingga mampu mengakomodasi kebutuhan selama pembelajaran. E-learning yang digunakan akan memungkinkan pengajar memantau partisipasi dan menilai kinerja peserta didik serta kolaborasi dengan menggunakan alat interaktif seperti konferensi video, forum diskusi yang pada akhirnya proses pembelajaran dapat dilaksanakan meski dalam situasi pandemic (Cheng \& Yuen, 2018). Untuk itu, sistem e-learning hendaknya perlu dibangun dan dikembangkan agar kompatibel sesuai dengan kebutuhan dan fungsinya, sehingga pembelajarann berjalan secara efektif serta memuaskan mahasiswa dan pada gilirannya akan mampu menunjang kinerja akademik (Cheng, 2019; Alyoussef, 2021a).

Kualitas informasi mengandung pengertian sejauh mana pengguna internet merasa yakin bahwa informasi internet tersebut up-to-date, akurat, relevan, tepat, lengkap, mudah diapahami dan mudah ditafsirkan. Kualitas informasi dalam penelitian ini ditinjau dari segi terkersediaan informasi yang terbarukan, akurat dan relevan. Hasil penelitian menunjukkan bahwa kualitas informasi berpengaruh signifikan terhadap kepuasan mahasiswa. Hal ini mengindikasikan bahwa kualitas informasi yang disediakan mampu meningkatkan kepuasan mahasiswa dalam proses pembelajaran e-learning. Kepuasan yang tercipta tersebut berupa mahasiswa merasa bahwa penggunaan e-learning selama pandemi adalah keputusan tepat dalam proses pembelajaran. Mahasiswa juga merasa bahwa e-learning dapat memenuhi harapan dalam proses pembelajaran sehingga secara keseluruhan mahasiswa puas dengan penerapan proses pembelajaran secara e-learning. Kualitas informasi yang mempunyai peran paling besar dalam meningkatkan kepuasan mahasiswa yaitu bahwa e-learning menyediakan informasi yang relevan. Hal ini ditunjukkan dengan nilai loading faktor paling tinggi yaitu 0,944. Jadi, peran TTF dan kualitas informasi sangatlah penting untuk meningkatkan kepuasaan mahasiswa dalam proses pembelajaran e_learning. Berdasarkan hasil ini dibutuhkan dukungan berbagai pihak untuk meningkatkan kepuasaan mahasiswa dalam proses pembelajaranya.

\section{SIMPULAN}

Berdasarkan hasil penelitian dan pembahasan, dapat disimpulkan bahwa pembelajaran $e$ learning melalui TTF dapat meningkatkan kepuasan mahasiswa. Semakin tinggi kualitas informasi dalam sistem pembelajaran e-learning Universitas Budi Luhur menyebabkan kepuasan mahasiswa akan semakin tinggi Untuk itu, pihak pengelola universitas perlu memerhatikan faktor-faktor pencetus kepuasan mahasiswa yaitu pemenuhan harapan pada proses pembelajaran secara e-learning. Terkait dengan TTF, pengelola perlu memerhatikan kesesuaian fungsi e-learning dengan proses pembelajaran. Kualitas informasi seperti penyedian informasi yang terorganisasi pada sistem e-learning juga perlu diperhatikan agar kepuasan pengguna yaitu mahasiswa dalam pembelajaran e-learning tercipta yang selanjutkan akan meningkatkan kinerja mahasiswa. 


\section{DAFTAR RUJUKAN}

Abbas, S. K., Aslam, B., Hashmi, Z. M., Majid, S., Ijaz, T., \& Latif, N. (2018). Testing the Impact of Mobile Banking on Individual Performance using Delone \& McLean and TTF Models. Global Scientific Journals, 6(7), 867-883.

Abrego Almazán, D., Sánchez Tovar, Y., \& Medina Quintero, J. M. (2017). Influence of Information Systems on Organizational Results. Contaduria y Administracion, 62(2), 321-338. https://doi.org/10.1016/j.cya.2017.03.001.

Akkoyunlu, B., \& Soylu, M. Y. (2008). A Study of Student's Perceptions in a Blended Learning Environment Based on Different Learning Styles. Educational Technology and Society, 11(1), 183-193. https://citeseerx.ist.psu.edu/viewdoc/download?doi=10.1.1.571.594\&rep=rep1\&type=pdf.

Al-Fraihat, D., Joy, M., Masa'deh, R., \& Sinclair, J. (2020). Evaluating E-Learning Systems Success: An Empirical Study. Computers in Human Behavior, 102(June 2019), 67-86. https://doi.org/10.1016/j.chb.2019.08.004.

Al-Maatouk, Q., Othman, M. S., Aldraiweesh, A., Alturki, U., Al-Rahmi, W. M., \& Aljeraiwi, A. A. (2020). TaskTechnology Fit and Technology Acceptance Model Application to Structure and Evaluate the Adoption of Social Media in Academia. IEEE Access, 8, 78427-78440. https://doi.org/10.1109/ACCESS.2020.2990420.

Al-Rahmi, A. M., Shamsuddin, A., \& Alismaiel, O. A. (2020). Task-Technology Fit Model: The Factors Affecting Students' Academic Performance in Higher Education. Universal Journal of Educational Research, 8(12), 6831-6843. https://doi.org/10.13189/ujer.2020.081249.

Al-Rahmi, W. M., Othman, M. S., \& Yusuf, L. M. (2015). Exploring the Factors that Affect Student Satisfaction through Using E-learning in Malaysian Higher Education Institutions. Mediterranean Journal of Social Sciences, 6(4S1), 299-310. https://doi.org/10.5901/mjss.2015.v6n4s1p299.

Al-Rahmi, W. M., Yahaya, N., Aldraiweesh, A. A., Alamri, M. M., Aljarboa, N. A., Alturki, U., \& Aljeraiwi, A. A. (2019). Integrating Technology Acceptance Model with Innovation Diffusion Theory: An Empirical Investigation on Students' Intention to Use E-Learning Systems. IEEE Access, 7, 2679726809. https://doi.org/10.1109/ACCESS.2019.2899368.

Alam, M. M., Ahmad, N., Naveed, Q. N., Patel, A., Abohashrh, M., \& Khaleel, M. A. (2021). E-Learning Services to Achieve Sustainable Learning and Academic Performance: An Empirical Study. Sustainability, 13(5), 1-20. https://www.mdpi.com/2071-1050/13/5/2653.

Almaiah, M. A., Al-Khasawneh, A., \& Althunibat, A. (2020). Exploring the Critical Challenges and Factors Influencing the E-learning System Usage During COVID-19 Pandemic. Education and Information Technologies, 25(6), 5261-5280. https://doi.org/10.1007/s10639-020-10219-y.

Almarashdeh, I. (2016). Sharing Instructors Experience of Learning Management System: A Technology Perspective of User Satisfaction in Distance Learning Course. Computers in Human Behavior, 63, 249-255. https://doi.org/10.1016/j.chb.2016.05.013.

Alyoussef, I. Y. (2021). E-Learning Acceptance: The Role of Task-Technology Fit as Sustainability in Higher Education. Sustainability, 13(11), 1-15. https://doi.org/10.3390/su13116450.

Amalia, S. R., \& Purwaningsih, D. (2020). Pengaruh Self Regulated Learning dan Web Course Berbantuan Google Classroom, Whatsapp Group terhadap Pemahaman Konsep. AKSIOMA: Jurnal Program Studi Pendidikan Matematika, 9(4), 917-925. https://doi.org/10.24127/ajpm.v9i4.3009.

Aparicio, M., Bacao, F., \& Oliveira, T. (2017). Grit in the Path to e-Learning Success. Computers in Human Behavior, 66, 388-399. https://doi.org/10.1016/j.chb.2016.10.009.

Cheng, D., Liu, G., Qian, C., \& Song, Y.-F. (2013). Customer Acceptance of Internet Banking: Integrating Trust and Quality with UTAUT Model. IEEE, 1(1), 383-388.

Cheng, M., \& Yuen, A. H. K. (2018). Student Continuance of Learning Management System Use: A Longitudinal Exploration. Computers and Education, 120, 241-253. https://doi.org/10.1016/j.compedu.2018.02.004.

Cheng, Y.-M. (2019). How Does Task-Technology Fit Influence Cloud-Based E-Learning Continuance and Impact? Education and Training, 61(4), 480-499. https://doi.org/10.1108/ET-09-2018-0203.

Cidral, W. A., Oliveira, T., Di Felice, M., \& Aparicio, M. (2018). E-learning Success Determinants: Brazilian Empirical Study. Computers and Education, 122, 273-290. https://doi.org/10.1016/j.compedu.2017.12.001.

Ferdinand, A. (2014). Metode Penelitian Manajemen : Pedoman Penelitian untuk Penulisan Skripsi, Tesis dan Disertasi Ilmu Manajemen (Edisi 5). Semarang: Badan Penerbit Universitas Diponegoro.

Gebauer, J., Shaw, M. J., \& Gribbins, M. L. (2010). Task-Technology Fit for Mobile Information Systems. Journal of Information Technology, 25(3), 259-272. https://doi.org/10.1057/jit.2010.10.

Ghozali, I. (2006). Aplikasi Analisis Multivariate dengan Program SPSS (1st ed.). Semarang: Badan Penerbit Universitas Diponegoro. 
Goodhue, D. L., \& Thompson, R. L. (1995). Task-Technology Fit and Individual Performance. MIS Quarterly, 19(2), 213-236. https://doi.org/10.1093/bib/bbp020.

Gorla, N., Somers, T. M., \& Wong, B. (2010). Organizational Impact of System Quality, Information Quality, and Service Quality. Journal of Strategic Information Systems, 19(3), 207-228. https://doi.org/10.1016/j.jsis.2010.05.001.

Hadi, L. (2020). Persepsi Mahasiswa terhadap Pembelajaran Daring di Masa Pandemik Covid-19 Student Perceptions of Online Learning During Covid-19 Pandemic. Jurnal Zarah, 8(2), 56-61. https://doi.org/10.31629/zarah.v8i2.2464.

Hair, J. F., Risher, J. J., Sarstedt, M., \& Ringle, C. M. (2019). When to Use and how to Report the Results of PLS-SEM. European Business Review, 31(1), 2-24. https://doi.org/10.1108/EBR-11-2018-0203.

Isaac, O., Abdullah, Z., Ramayah, T., \& Mutahar, A. M. (2017). Internet Usage, User Satisfaction, TaskTechnology Fit, and Performance Impact among Public Sector Employees in Yemen. International Journal of Information and Learning Technology, 34(3), 210-241. https://doi.org/10.1108/IJLT11-2016-0051.

Isaac, O., Abdullah, Z., Ramayah, T., \& Mutahar, A. M. (2018). Factors Determining User Satisfaction of Internet Usage among Public Sector Employees in Yemen. International Journal of Technological Learning, Innovation and Development, 10(1), 37-68. https://doi.org/10.1504/IJTLID.2018.091800.

Kanellou, A., \& Spathis, C. (2013). Accounting Benefits and Satisfaction in an ERP Environment. International Journal of Accounting Information Systems, 14(3), 209-234. https://doi.org/10.1016/j.accinf.2012.12.002.

Latan, H., \& Ghozali, I. (2016). Partial Least Squares: Konsep, Metode dan Aplikasi Menggunakan Program WarpPLS 5.0 (Edisi 3). Badan Penerbit Universitas Diponegoro.

Main Uddin, Ghosh, A., \& Isaac, O. (2019). Impact of the System, Information, and Service Quality of Online Learning on User Satisfaction among Public Universities Students in Bangladesh. International Journal of Management and Human Science (IJMHS), 3(2), 1-10. https://ejournal.lucp.net/index.php/ijmhs/article/view/784.

Mohammadi, H. (2015). Investigating Users' Perspectives on E-Learning: An Integration of TAM and IS Success Model. Computers in Human Behavior, 45, 359-374. https://doi.org/10.1016/j.chb.2014.07.044.

Montesdioca, G. P. Z., \& Maçada, A. C. G. (2015). Measuring User Satisfaction with Information Security Practices. Computers and Security, 48, 267-280. https://doi.org/10.1016/j.cose.2014.10.015.

Moore, J. C. (2011). A Synthesis of Sloan-C Effective Practices. Journal of Asynchronous Learning Network, 16(1), 91-115. https://doi.org/10.24059/olj.v13i4.1649.

Navarro, M. M., Prasetyo, Y. T., Young, M. N., Nadlifatin, R., \& Redi, A. A. N. P. (2021). The Perceived Satisfaction in Utilizing Learning Management Systems among Engineering Students during the COVID-19 Pandemic: Integrating Task Technology Fit and Extended Technology Acceptance Model. Sustainability (Switzerland), 13(19), 2-18. https://doi.org/10.3390/su131910669.

Osang, F. B. (2019). Open Educational Resources: Determining Task Technology Fit (TTF) Impact on Faculty Usage, Satisfaction and Performance. International Journal of Human and Technology Interaction, 3(2), 35-46.

Pakpahan, R., \& Fitriani, Y. (2020). Analisa Pemafaatan Teknologi Informasi dalam Pembelajaran Jarak Jauh di Tengah Pandemi Virus Corona Covid-19. JISAMAR (Journal of Information System, Applied, Management, Accounting and Researh), 4(2), 30-36. http://journal.stmikjayakarta.ac.id/index.php/jisamar/article/view/181.

Permana, I. B. G. A., \& Setianto, D. P. (2017). Pengaruh Task Technology Fit, System Quality dan Information Quality terhadap User Performance: Perceived Usefulness dan Perceived Ease of Use sebagai Pemediasi. Jurnal Manajemen Teori Dan Terapan, 10(3), 231-242. https://doi.org/10.20473/jmtt.v10i3.7058.

Ramírez-Correa, P. E., Rondan-Cataluña, F. J., Arenas-Gaitán, J., \& Alfaro-Perez, J. L. (2017). Moderating Effect of Learning Styles on a Learning Management System's Success. Telematics and Informatics, 34(1), 272-286. https://doi.org/10.1016/j.tele.2016.04.006.

Sari, Y. I., \& Trisnawati, N. (2021). Analisis Pengaruh E-Learning dan Kesiapan Belajar terhadap Minat Belajar Melalui Motivasi Belajar sebagai Variabel Intervening Mahasiswa Program Beasiswa FLATS di Surabaya pada Masa Pandemi Covid-19. Jurnal Kependidikan, 7(2). https://doi.org/10.33394/jk.v7i2.3736.

Sawangchai, A., Prasarnkarn, H., Kasuma, J., Polyakova, A. G., \& Qasim, S. (2020). Effects of Covid-19 on Digital Learning of Entrepreneurs. Polish Journal of Management Studies, 22(2), 502-517. https://doi.org/10.17512/pjms.2020.22.2.33. 
Setiaji, B. (2004). Riset dengan Pendekatan Kuantitatif. Muhammadiyah University Press.

Supriyanto, A. S., \& Maharani, V. (2013). Metode Penelitian Manajemen Sumber Daya Manusia. UIN-MALIKI Press Malang.

Tam, C., \& Oliveira., T. (2016). Performance Impact of Mobile Banking: Using Task-Technology Fit (TTF) Approach. Internasional Journal of Bank Marketing, 34(4), 434-457. https://doi.org/10.1108/IJBM-11-2014-0169.

Wang, Y.-S., \& Liao, Y. W. (2008). Assessing eGovernment Systems Success: A Validation of the DeLone and McLean Model of Information Systems Success. Government Information Quarterly, 25(4), 717733. https://doi.org/10.1016/j.giq.2007.06.002.

Wardani, K. R. N. (2019). Penerapan Task-Technology Fit terhadap Kinerja Guru SMK Negeri 1 Indralaya Selatan. Page 1 JUSIM (Jurnal Sistem Informasi Musirawas), 4(2), 116-126. http://jurnal.univbinainsan.ac.id/index.php/jusim/article/view/638.

Wu, B., \& Chen, X. (2017). Continuance Intention to Use MOOCs: Integrating the Technology Acceptance Model (TAM) and Task Technology Fit (TTF) Model. Computers in Human Behavior, 67, 221-232. https://doi.org/10.1016/j.chb.2016.10.028.

Wu, J. H., \& Wang, Y. M. (2006). Measuring KMS Success: A Respecification of the DeLone and McLean's Model. Information and Management, 43(6), 728-739. https://doi.org/10.1016/j.im.2006.05.002.

Yi, Y. J., S. Y., \& Bae., B. J. (2016). 2016. The Influence of Smartphone on Academic Performance the Development of the Technology-to-Performance Chain Model. Library Hi Tech, 34(3), 480-499. https://doi.org/10.1108/LHT-04-2016-0038. 